\title{
Antioxidant activity in endophytic fungi isolated from Gynostemma pentaphyllum Makino
}

\author{
SHANG Fei ${ }^{1, a}$, WANG Chunlin ${ }^{1, b}$, WANG Hui ${ }^{2, c}$ \\ ${ }^{1}$ College of Life Science and Technology, Longdong University, Qingyang 745000, Gansu \\ ${ }^{2}$ College of Agriculture and Forestry, Longdong University, Qingyang 745000, Gansu
}

\begin{abstract}
Gynostemma pentaphyllum Makino is a well known edible and medicinal plant in oriental countries, its dominant active constituents are mainly Gypenosides(GP). Endophytic fungi with antioxidant activity were screened and identified from gynostemma pentaphyllum, and gynostemma pentaphyllum saponin (GP) was used as host. A total of 10 strains of endophytic fungi were isolated from the root of healthy, living, and symptomless tissues of Gynostemma pentaphyllum Makino. The extract from a strain (G4) showed antioxidant activity and had the same RF value in TLC, because the retention time of real gynostemma pentaphyllum saponin (GP) and its extract was the same as that of natural gynostemma pentaphyllum (GP) in HPLC. So the strain G4 of endophytic fungus appears to produce the same components as its host.
\end{abstract}

\section{Introduction}

Gynostemma pentaphyllum Makino is a well known edible and medicinal plant in oriental countries ${ }^{[1-2]}$, and is known as 'Jiao-Gu-Lan' in China, "Cha-Satun" in Thailand, and "Amachazuru" in Japan ${ }^{[3]}$. Recently, Gynostemma pentaphyllum Makino has attracted great attention owing to its anti-tumor activities ${ }^{[4]}$, immunomodulatory effect ${ }^{[5]}$, anti-gastric ulcer effect, treating hyperlipidemia, and anti-oxidant properties ${ }^{[6]}$, and has been described as having minimal toxicity ${ }^{[7]}$. Therefore, the G. pentaphyllum green tea is presently promoted in China and is sold in Europe as an herbal tea which is "advantageous to one's health and beauty"' ${ }^{[8-9]}$. The presence of saponins and flavonoids in G. pentaphyllum as functional components is believed to be responsible for this health-enhancing effect. Because of the similarity in bioactive components to ginseng root, $\mathrm{G}$. pentaphyllum was named as "second ginseng".

Endophytes are a kind of inadequately studied microorganisms, which are rich and reliable sources of biological activities and new chemical compounds. they have the potential to be developed in a variety of medical, agricultural and industrial fields. Fungal endophytes are also considered to be repositories of new secondary metabolites, some of which have beneficial biological activities. Recent studies have shown that fungal endophytes are ubiquitous in plant species ${ }^{[10]}$.

The aim of the present study is to select and identify endophytic fungus from Gynostemma pentaphyllum Makino which displays antioxidant activity and produces the same component of Gypenosides (GP) as their host.

\section{Materials and methods}

\subsection{Collection of plant material}

The materials were collected from the campus of Shaanxi Normal University, xi'an, Shaanxi, China in 2010 March. After plant selection, disease free parts of the roots were cut with the help of a sterile scalpel and placed in sterile plastic bags. All the samples were immediately brought to the laboratory for further process.

\subsection{Isolation of endophytic fungi}

Samples of fresh root of Gynostemma pentaphyllum Makino was thoroughly washed using distilled water, followed by $75 \%$ ethanol for $5 \mathrm{~min}$ and $2.5 \%$ sodium hypochlorite for $7 \mathrm{~min}$ to accomplish surface sterilization. then subsequently rinsed in sterile demineralized water. Small pieces of inner tissues were placed on potato dextrose agar (diced potatoes, 300g/l, dextrose,20g/l, agar,20g/l) supplemented with antibiotic streptomycin $(50 \mu \mathrm{g} / \mathrm{ml})$ and penicillium $(50 \mu \mathrm{g} / \mathrm{ml})$ in petri plates and incubated at $28^{\circ} \mathrm{C}$ until the fungal was grown out. The pure culture were obtained using routine microbiological methods and stored at $4{ }^{\circ} \mathrm{C}$.

\subsection{Pretreatment of separated fungal fermentation broth}

All the endophytic fungi were cultivated in $200 \mathrm{ml}$ PDB for $7 \mathrm{~d}$ at $28^{\circ} \mathrm{C}$, and each fermentation broths were centrifugalized at $5000 \mathrm{r} / \mathrm{min}$ for $30 \mathrm{~min}$ to separate 
mycelium pellets from supernatant. the mycelium pellets were dried up, extracted with alcohol, grinded by ultrasonic cell disintegrator $\left(300 \mathrm{~W}, 20^{\circ} \mathrm{C}, 10 \mathrm{~min}\right)$ in order to release the metabolites of the inside-cell completely. The supernatants were extracted 2 times with water saturated butanol, all extractions were mixed together and concentrated in a rotary evaporator, which were dissolved with alcohol for further analysis.

\subsection{Preparation of herbs extract}

The cleaned plants were dried in a hot air oven at $80^{\circ} \mathrm{C}$, fine powder of the plant $(20 \mathrm{~g})$ was obtained by a mill and extracted into ethanol for $3 \mathrm{~h}$ at $80{ }^{\circ} \mathrm{C}$, at $1: 10$ ratio of powder to ethanol. after two cycles, the combined extracts were pooled, concentrated using a rotary evaporator, the reserved solvent was removed absolutely in a water bath at $80{ }^{\circ} \mathrm{C}$. A small portion of the extraction cream was dissolved in absolute ethanol to prepare stock solutions $(3 \mathrm{mg} / \mathrm{ml})$ and others were extracted 2 times with water saturated butanol, the extraction cream and stock solutions were acquired following the above method.

\subsection{Antioxidant activity test}

The DPPH radical scavenging activity was determined according to the methods described by Yangping Zhang. $2 \mathrm{ml}$ of the DPPH solution (0.2m DPPH in ethanol) and the same amount of sample (dissolved with ethanol) mixing was shaken and let stand for $30 \mathrm{~min}$ at room temperature. The absorbance was recorded at $517 \mathrm{~nm}$ using a spectrophotometer. Crude herbs extracts was used as the positive control. the DPPH radical scavenging activity was calculated according to: Scavenging activity $(\%)=[1-(\mathrm{Ai}-\mathrm{Aj}) / \mathrm{Ac}] \times 100$.

where Ac is the absorbance of the control (ethanol instead of sample), $\mathrm{Ai}$ is the absorbance of the sample, and $\mathrm{Aj}$ is the absorbance of the sample only (ethanol instead of DPPH).

The reducing power was measured according to the method of Oyaizu with some modifications. the mixture of sample $(2.5 \mathrm{ml}$, dissolved with ethanol), sodium phosphate buffer $\left(2.5 \mathrm{ml}, 0.2 \mathrm{M}\right.$, pH 6.6) and $\mathrm{K}_{3} \mathrm{Fe}(\mathrm{CN})_{6}$ $(2.5 \mathrm{ml}, 1 \%, \mathrm{w} / \mathrm{v})$ was incubated at $50^{\circ} \mathrm{C}$ for $20 \mathrm{~min}$. A portion of trichloroacetic acid $(2.5 \mathrm{ml}, 10 \% \mathrm{w} / \mathrm{v})$ was added to the mixture, which was then centrifugated at $5000 \mathrm{rpm}$ for $10 \mathrm{~min}$. The upper layer $(5 \mathrm{ml})$ was mixed with $5 \mathrm{ml}$ of fresh $\mathrm{FeCl} 3(0.02 \%, \mathrm{w} / \mathrm{v})$, and the absorbance was measured at $700 \mathrm{~nm}$. Stock solution of the crude herbs extracts was used as the positive control by diluting to concentration gradient. A higher absorbance indicates a higher reducing power.

\subsection{Identification of total glycosides of gynostemma pentaphyllum by (GP) (TLC and HPLC)}

20 samples (outside and inside the cell) from the strains were spotted onto precoated GF254 silica-gel plate, together with authentic Gypenosides (GP). Then the plates were developed in a solvent system of the below solution of chloroform-methanol-water $(13: 7: 2)$ at $4{ }^{\circ} \mathrm{C}$ overnight. subsequently the spots were detected under the ultraviolet (UV $365 \mathrm{~nm}$ ) light after $10 \% \mathrm{H}_{2} \mathrm{SO}_{4} / \mathrm{ETOH}$ solution sprayed as display solvent and 3-5minutes heated at $105^{\circ} \mathrm{C}$. Values of the samples were measured and compared in order to achieve a primary identification of Gypenosides (GP).

Extracts from the selected strains were filtered through $0.22 \mu \mathrm{m}$ membrane. HPLC was done with a HPLC system (LC-2010A); a Dikma Diamonsil-C18 chromatographic column $(5 \mu \mathrm{m}, 250 \mathrm{~mm}$ x $4.6 \mathrm{~mm})$; mobile phase acetonitrile/water (3:7, v/v); sample injection volume $10 \mathrm{ul}$; flow rate: $0.8 \mathrm{ml} / \mathrm{min}$; temperature: $30^{\circ} \mathrm{C}$; detection wavelength $203 \mathrm{~nm}$.

\section{Results and discussions}

\subsection{Isolation of endophytic organism}

Ten endophytic fungal strains were isolated from the roots of Gynostemma pentaphyllum Makino.

\subsection{Antioxidant activity test}

The model of scavenging DPPH radical is a widely used method to evaluate the free radical scavenging activities of antioxidants. In the DPPH assay, the antioxidants are able to reduce the stable DPPH radical (purple) to the non-radical form DPPH-H (yellow). The DPPH scavenging activities of antioxidants are attributed to their hydrogen donating abilities.

The reducing power of a compound may serve as a significant indicator of its potential antioxidant activity. In the reducing power assay, antioxidants are able to reduce $\mathrm{Fe}^{3+} /$ ferricyanide complex to its ferrous form. Therefore, $\mathrm{Fe}^{2+}$ can monitored by measuring the formation of Perl's Prussian blue at $700 \mathrm{~nm}$.

As shown in Fig.1, the scavenging activities on DPPH radicals(Fig.1A) and reducing power (Fig.1B)of $\mathrm{NEH}, \mathrm{AEH}$ and AM4 increased with the increase of concentrations, respectively, and at a concentration of $3.0 \mathrm{mg} / \mathrm{ml}$, the DPPH scavenging activities for $\mathrm{NEH}$, AEH and AM4 were 92.96\%, 97.86\%, and 43.14\%, and the DPPH scavenging activities and reducing power of AM4 tested were much lower than NEH and AEH. These results indicated that endophytic fungi G4 isolated from Gynostemma pentaphyllum Makino displays antioxidant activity as its host, however, the antioxidant activity was much lower. The antioxidant activities of herbs' alcohol extracts was higher than that of its n-butanol extracts, This was probably due to the presence of other antioxidant components in the alcohol extracts. 


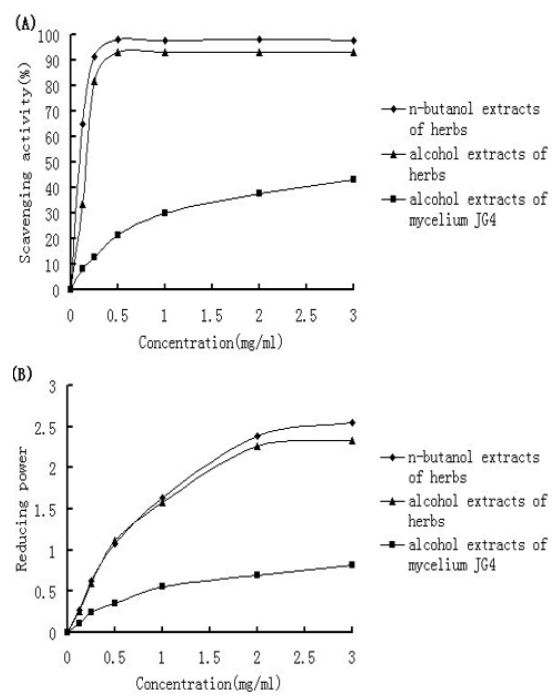

Fig.1 The DPPH scavenging activities (A) of extracts from n-butanol extracts of herbs (NEH), alcohol extracts of herbs (AEH) and mycelium JG4(AM4). The reducing power(B) of $\mathrm{NEH}, \mathrm{AEH}$ and AM4.

\subsection{Thin layer chromatographic analysis}

Fermention extract of the 10 strains, both inside and outside the cell, was detect by TLC analysis to select whether anyone could produce Gypenosides (GP). According to the TLC result, only the strain labeled as G4 (extract inside cell) produced a spot under UV light (365nm), with the same $\mathrm{Rf}$ value as the authentic Gypenosides(GP). Therefore, we inferred that G4 (extract inside cell) might produce Gypenosides (GP), and further HPLC analysis should be carried on to make exactitude identification.

\subsection{High performance liquid chromatographic analysis}

The HPLC results showed that the samples G4 (inside cell) and authentic Gypenosides(GP) had the same retention time of about $17 \mathrm{~min}$. Therefore, on the basis of the results described above, we inferred that the samples from strain G4 (inside cell) may produce the bioactive compound Gypenosides (GP). As shown in Figure 2.

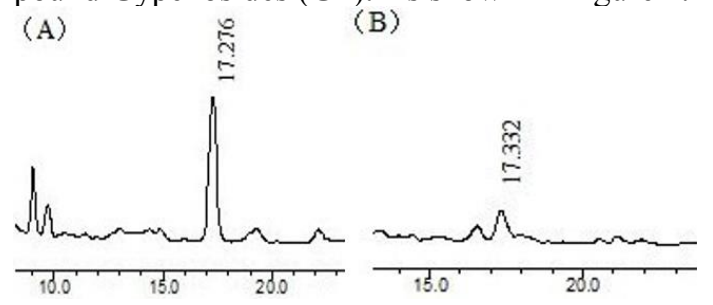

Fig.2 A. HPLC graph of authentic Gypenosides; B. HPLC graph of intracellular products of G4.

\section{Conclusion}

(1) Ten strains of endophytic fungi of gynostemma pentaphyllum were isolated from the root tissue of gynostemma pentaphyllum by conventional microbial isolation and purification methods, and showed some morphological diversity.

(2) G4 strain was successfully screened as endophytic fungus producing gynostemma pentaphyllum saponins by TLC and HPLC methods. TLC results showed that the intracellular products of G4 strain had the same RF value as the standard, and HPLC results showed that the intracellular products of G4 had the same absorption peak (18min) as the standard. It is inferred that G4 strain can produce similar or the same active components as the host.

The production of Gypenosides(GP) by G4 supports the theory that endophytes adapted themselves to their special microenvironments by genetic variation, including uptake of some plant DNA into their own genomes during the long coevolution of endophytes and their host plants. This could have led to the ability of certain endophytes to biosynthesise some phytochemicals originally associated with the host plant. Therefore, it is possible to isolate endophytes from plants and select the host-specificity, which is also an promising candidate for natural active material.

\section{Author's background}

\begin{tabular}{|c|c|c|c|}
\hline $\begin{array}{c}\text { Your } \\
\text { Name }\end{array}$ & Title* & Research Field & $\begin{array}{c}\text { Personal } \\
\text { website }\end{array}$ \\
\hline $\begin{array}{c}\text { SHANG } \\
\text { Fei }\end{array}$ & $\begin{array}{c}\text { senior } \\
\text { lecture }\end{array}$ & Microbiology & \\
\hline $\begin{array}{c}\text { WANG } \\
\text { Chunlin }\end{array}$ & $\begin{array}{c}\text { associate } \\
\text { professor }\end{array}$ & Plant physiology & \\
\hline $\begin{array}{c}\text { WANG } \\
\text { Hui }\end{array}$ & $\begin{array}{c}\text { senior } \\
\text { lecture }\end{array}$ & $\begin{array}{c}\text { Food safety } \\
\text { engineering }\end{array}$ & \\
\hline
\end{tabular}

\section{References}

1. Hu Lihong, Chen Zhongliang, Xie Yuyuan. New triterpenoid saponins from cynosternma pentophyllum[J]. Journal of Natural Products, 1996, 59:1143-1145.

2. Takemoto T, Arihara S, Yoshikawa K, et al. Studies on the Constituents of Cucurbitaceae Plants. VII. On the Saponin Constituents of Gynostemma pentaphyllum MAKINO. (3) [J]. Yakugaku Zasshi, 1984, 104(4):325-331.

3. Lv Y, Yang X, Zhao Y, et al. Separation and quantification of component monosaccharides of the tea polysaccharides from Gynostemma pentaphyllum by HPLC with indirect UV detection[J]. Food Chemistry, 2009, 112(3):742-746.

4. H.H. Zhou, J.X. Liang, W.H. Hu. An experimental study of the anti tumour effect of Jiaogulan and Oolong Tea[J]. Journal of Xiamen University, 2001, 40(4):990-993.

5. X.H. Qian, Y.X. Wang, X.L Tang. Effects of Gynostemma pentaphllum Makino polysaccharide (PGP) on immunefunction[J]. Journal of China Pharmaceutical University, 1998, 30(1):51-53.

6. Cai T S, Zhang S F, Wang M C. Anti-oxidation effect 
of gypenosides in aged rats[J]. Chinese Journal of Clinical Rehabilitation, 2005, 9(35):106-107.

7. Attawish A, Chivapat S, Phadungpat S, et al. Chronic toxicity of Gynostemma pentaphyllum[J]. Fitoterapia, 2004, 75(6):539-551.

8. Takemoto T., Arihara S., Nakajima T., et al. Studies on the Constituents of Gynostemma pentaphyllum MAKINO. 1. Structures of gypenoside 1-XIV[J]. Yakugaku Zasshi Journal of the Pharmaceutical Society of Japan, 1983,103:173-185.

9. Rujjanawate C, Kanjanapothi D, Amornlerdpison D. The anti-gastric ulcer effect of Gynostemma pentaphyllum Makino[J]. Phytomedicine, 2004, 11(5):431-435.

10. Germaine K, Keogh E, Garcia-Cabellos G, et al. Colonisation of poplar trees by gfp expressing bacterial endophytes[J]. FEMS Microbiology Ecology, 2004, 48(1):109-118. 